\title{
ANALISA STRUKTUR OKSIDA GRAFENA TEREDUKSI
}

\section{Structural Analysis Of Reduced Graphene Oxide}

\author{
Fataa Kusumattaqiin ${ }^{1}$, Ramli ${ }^{1}$, Noorma Kurnyawaty ${ }^{1}$, Abdul Halik ${ }^{2}$, Tauhid Hira ${ }^{3}$ \\ ${ }^{1}$ Jurusan Teknik Kimia, Politeknik Negeri Samarinda \\ ${ }^{2}$ Jurusan Teknik Mesin, Politeknik Negeri Samarinda \\ ${ }^{3}$ Jurusan Pariwisata, Politeknik Negeri Samarinda \\ email :fataakusumattaqiin@polnes.ac.id
}

\begin{abstract}
Abstrak. Oksida grafena tereduksi telah berhasil diproduksi dari oksida grafena dengan menggunakan asam format sebagai agen pereduksi. Tujuan penelitian ini untuk mensintesis oksida grafena tereduksi. Banyak penelitian yangc menunjukkan bahwa material ini memiliki sifat-sifat fisika yang baik. Dalam penelitian ini menggunakan metode modifikasi Hummer untuk menghasilkan oksida grafena. Selanjutnya direduksi dengan asam format untuk mendapatkan oksida graphene tereduksi. Hasil penelitian dengan menggunakan FT-IR menunjukkan bahwa oksida grafena tereduksi dengan puncak tertentu (gugus fungsi oksigen) secara besar berkurang intensitasnya setalah direduksi dengan asam format. Sementara itu, karakterisasi dengan XRD menunjukkan $d$-spacing berkurang dari $7.75 \AA$ menjadi $4.00 \AA ̊$. Ini dapat dijelaskan karena pengurangan gugus fungsi oksigen. Kemudian hasil penghalusan Le Bail menunjukkan sampel mengadopsi ruang grup P B C A. Perubahan parameter kisi ditemukan setelah oksidasi dan reduksi, khususnya pada parameter $a$ dan $b$. Parameter $a$ dan $b$ menunjukkan panjang sisi tepi dari sistem kristal.
\end{abstract}

Kata Kunci : FT-IR, XRD, Metode Le Bail, Oksida Grafena Tereduksi

\begin{abstract}
The reduced graphene oxide (RGO) was successfully produced from graphene oxide (GO) by using formic acid as a reducing agent. This research was aimed to synthesize reduced graphene oxide. A lot of studies showed that RGO has excellent physical properties. In this research used Hummer modified method to produce graphene oxide. Then, it was reduced by formic acid to obtain reduced graphene oxide. The research results by using FT-IR showed that reduced graphene oxide with certain peaks (with oxygen functional groups) were greatly reduced in intensity after reduction with formic acid. Meanwhile, XRD characterization showed the d-spacing decreased from $7.75 \AA$ to $4.00 \AA$. This can be described due to a removal of oxygen functional group. Then Le Bail's refinement exhibited samples adopted space group P B C A. Changes in lattice parameters were found after oxidation and reduction, especially $a$ and $b$. The parameter of $a$ and $b$ can be defined as edge lengths of crystal system.
\end{abstract}

Keywords : FT-IR, XRD, Le Bail's method, Reduced Graphene Oxide 


\section{PENDAHULUAN}

Grafena adalah lapisan tunggal atom karbon terhibridisasi $\mathrm{sp}^{2}$ dengan kisi heksagonal (Daniel et al., 2009). Oksida grafena banyak menarik perhatian karena memilki sifat termal, mekanik dan elektrik yang baik. Oksida grafena saat ini banyak digunkan sebagai zat antara dalam pembuatan grafena (Su \& Chiou, 2014). Pada oksida grafena, ada gugus epoksi dan hidroksi pada permukaan dan gugus karboksil di tepi (Lerf, He, \& Kilnowski, 1998). Dengan menggunakan teknik mekanik dan reduksi bahan kimia, gugus fungsi yang mengandung oksigen dapat dihilangkan.

Oksida grafena tereduksi adalah strukutur turunan dari grafena. Ada beberapa prosedur yang dapat digunakan untuk mereduksi oksida grafena.

a. Annealing Termal

Schniepp et al (Schniepp et al., 2006) dan Wu et al (Wu et al., 2009) melaporkan bahwa oksida grafena dapat direduksi dangan annealing termal pada suhu di bawah 2000 ${ }^{\circ} \mathrm{C}$. Reaksi samping dari prosedur ini menghasilkan gas $\mathrm{CO}$ dan $\mathrm{CO}_{2}$. Kudin et al (Kudin et al., 2007) melaporkan bahwa metode ini tidak disarankan karena menyebabakan kerusakan pada lapisan grafena yang disebabakan oleh pelepasan $\mathrm{CO}_{2}$. Diperkirakan $30 \%$ berat hilang dengan menggunakan metode ini.

b. Reduksi Dengan Bahan Kimia

Metode ini dipercaya paling efisien karena dapat diproduksi dengan biaya yang murah dan dapat dihasilkan dalam skala yang besar. Bahan kimia yang umum digunakan adalah hidrazin dan reduksi solvo-termal. Dubin et al (Dubin et al., 2010) mensintesis oksida grapehene tereduksi dengan solvo-termal dengan menggunkakan $\mathrm{N}$-methyl-2pyrrolidone (NMP) selama 24 jam pada suhu $200{ }^{\circ} \mathrm{C}$ dengan kondisi tanpa oksigen. Park et al (S. Park et al., 2011) melaporkan bahwa reaksi reduksi grafit dan oksida grafena dengan hidrazin memberikan perbedaaan sifat kimia dan struktur. Berdasarkan analisis elemen, rasio $\mathrm{C} / \mathrm{O}$ dari oksida grafit tereduksi adalah sekitar 5.0 dan pada oksida grafena tereduksi sekitar 10.2. Hasil ini menunjukkan derajat reduksi pada oksida grafit tereduksi kurang dari oksida grafena tereduksi. Stankovich et al (Stankovich et al., 2007) mengilustrasikan modifikasi struktur dari grafit menjadi struktur tereduksi seperti pada gambar berikut.

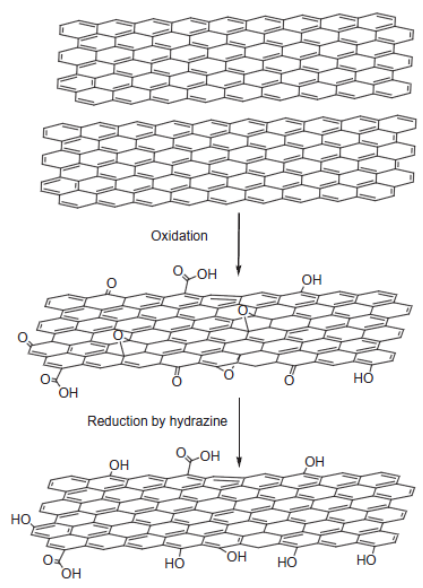

(a) 


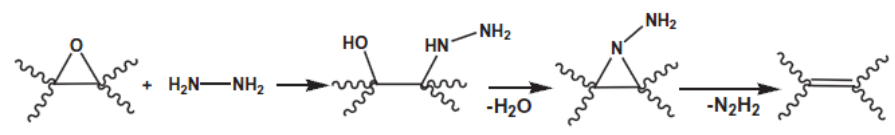

(b)

\section{Gambar 1. (a) Oksidasi grafit menjadi oksida grafena dan reduksi yang menghasilkan oksida grefena tereduksi (b) Jalan reaksi yang diusulkan untuk proses reduksi epoksi oleh hidrazin}

Park et al (O. K. Park et al., 2012) melaporkan bahwa perbandinagn daya hantar listrik turunan grafena dan oksida grafena tereduksi adalah $8000 \mathrm{~S} / \mathrm{m}$ dan sementara itu oksida grafena $3.7 \times 10^{-5} \mathrm{~S} / \mathrm{m}$. Dengan demikian menunjukkan potensi oksida grafena tereduksi lebih konduktif dibandingkan dengan oksida grafena. Hal ini yang menjadi tujuan reduksi yakni menghilangkan gugus epoksida yang seperti terlihat pada gambar 1 yang selanjutnya akan meningkatkan konduktifitas.

Pada penelitian ini, untuk menghasilkan oksida grafena tereduksi, menggunakan metode modifikasi Hummer. Kemudian produk yang dihasilkan direduksi dengan menggunkan asam format. Mitra et al (Mitra, Chatterjee, Kargupta, Ganguly, \& Banerjee, 2013) melaporkan bahwa metode ini mudah, kurang tingkat keracunannya, murah dan bebas logam. Adapun perbedaan dari metode Mitra et al yakni menggunakan durasi solvo-termal yang lebih lama hingga 2 hari yang diharapkan proses reduksi lebih intens. Disamping itu, belum ada studi pengaruh proses oksidasi dan reduksi terhadap perubahan parameter kisi system kristal menggunakan software Rietica dengan metode Le Bail.

\section{METODE PENELITIAN \\ Bahan Dan Alat}

Bahan mentah dari oksida grafena tereduksi adalah bubuk grafit yang disuplai oleh Thermo Fisher. Kemudian bahan kimia yang lain seperti sodium nitrate $\left(\mathrm{NaNO}_{3}\right)$, potassium permanganate $\left(\mathrm{KMnO}_{4}\right)$, ortho-phosphoric acid $\left(\mathrm{H}_{3} \mathrm{PO}_{4}\right)$, sulfuric acid $\left(\mathrm{H}_{2} \mathrm{SO}_{4}\right)$, hydrogen peroxide $\left(\mathrm{H}_{2} \mathrm{O}_{2}\right)$, formic acid $(\mathrm{HCOOH})$ dan ethanol dengan tingkat analtik. Kemudian karakterisasi XRD dilakukan dengan menggunakan alat Miniflex diffractometer, dengan sumber radiasi $\mathrm{CuK} \alpha(1.5405 \AA)$. Sementara karakterisasi FT-IR menggunakan alat Nicolet 6700 FTIR, Thermo Scientific.

\section{Tempat Penelitian}

Penelitian ini telah dilakukan di Laboratorium King Mongkut's University of Technology Thonburi (Thailand)

\section{Prosedur \\ Persiapan Oksida Grafena}

Oksida grafena dipersiapakan dengan menggunakan metode modifikasi Hummer (Hummers \& Offeman, 1958). Bubuk grafit digunakan sebagai bahan mentah. 9 gr bubuk grafit ditambhakan dengan 2.5 gr $\mathrm{NaNO}_{3}$. Kemudian, $\mathrm{H}_{2} \mathrm{SO}_{4}$ dan $\mathrm{H}_{3} \mathrm{PO}_{4}$ ditambahkan ke dalam suspensi dengan perbandingan $103.5 \mathrm{~mL}$ dan $11.5 \mathrm{~mL}$, atau denga rasio 9:1 (v:v). Suspensi diaduk dengan mebggunakan pengaduk mekanis dengan 
biarkan dalam water bath selama 30 menit. Selama pengadukan mekanis, suspensi ditambahkan dengan $15 \mathrm{gr} \mathrm{KMnO}_{4}$ dan suhu dijaga dibawah $20^{\circ} \mathrm{C}$ selama 30 menit dan kemudian tempatkan pada suhu ruang. Pada keadaan itu, suspensi berubah menjadi pasta. Sebanyak 230 air destilasi ditambhakan dan suhu dinaikan hingga $98{ }^{\circ} \mathrm{C}$ dengan menggunakan hot plate. Tahap selanjutnya, pasta diencerkan dengan $600 \mathrm{~mL}$ air hangat dan ditambahkan dengan $150 \mathrm{~mL}$ larutan $3 \% \mathrm{H}_{2} \mathrm{O}_{2}(\mathrm{w} / \mathrm{v})$ hingga suspensi diperoleh. Langkah selanjutnya, suspensi disentrifugasi, dan endapan dibilas dengan air destilasi dengan dikeringkan dengan menggunakan pompa vakum pada suhu $40^{\circ} \mathrm{C}$. Oksida grafit diperoleh pada tahapan ini. Oksida grafit kering kemudian dicampukan dengan etanol hingga diperoleh $2.5 \mathrm{~g} / \mathrm{cm}^{3}$ suspensi. Akhirnya, suspensi yang diperoleh, didispersi dengan bantuan proses ultrasonikasi dan biarkan pada suhu ruang.

\section{Reduksi Oksida Grafena}

Oksida grafena tereduksi dihasilkan dengan menggunakan metode yang dijelaskan oleh Mitra et al (Mitra et al., 2013). $30 \mathrm{~mL}$ suspensi methanol-oksida grafena $\left(2.5 \mathrm{mg} / \mathrm{cm}^{3}\right)$ diencerkan dengan menggunakan air tanpa mineral hingga volumenya 250 $\mathrm{mL}$. Tambahkan $100 \mathrm{ml}$ asam format ke dalam suspensi. Campuran dijaga pada suhu $100^{\circ} \mathrm{C}$ selama dua hari. Warna suspensi berubah menjadi hitam. Kemudian produk disaring, dan dikeringkan dengan menggunakan vakum pada suhu $40^{\circ} \mathrm{C}$ hingga beratnya konstan (6 jam).

\section{Karakterisasi \\ Difraksi Xrd}

Untuk menentukan struktur kristal, bubuk grafit, oksida grafena dan oksida grafena tereduksi dikarakterisasi dengan menggunakan Miniflex diffractometer, dengan sumber radiasi $\mathrm{CuK} \alpha(1.5405 \AA$ ). Data XRD dihaluskan dengan menggunakan software Rietica untuk memperoleh parameter kisi.

\section{FT-IR}

Untuk menentukan gugus fungsi dari bubuk oksida grafena dan oksida grafena tereduksi, maka dilakukan karaterisasi dengan menggunakan FT-IR. Alat yang digunakan Nicolet 6700 FTIR, Thermo Scientific. Sampel dicampurkan dengan $\mathrm{KBr}$ dengan perbandingan 1:99 (b/b). Specktra direkam dengan mode transmission dari 400 hingga $4000 \mathrm{~cm}^{-1}$ at $4 \mathrm{~cm}^{-1}$ dengan resolusi 32 pindai/sampel.

\section{HASIL DAN PEMBAHASAN}

Oksida grafena tereduksi berhasil diproduksi. Hasil ini dikonfirmasi dengan hasil karaketrisasi menggunakan FT-IR dan XRD.

\section{Karakterisasi FT-IR}

Untuk mengkonfirmasi telah dihasilkan oksida grafena dan oksida grephene tereduksi, maka perlu konfirmasi dengan spektra FT-IR. Adapun indikasi terjadinya proses reduksi dapat dilihat pada Tabel 1 . 
Tabel 1. Rangkuman Spektra FT-IR pada Oksida Grafena dan Oksida Grafena Tereduksi

\begin{tabular}{cccccc}
\hline Sumber & $\begin{array}{c}\text { Vibrasi } \\
\text { gugus } \mathbf{~ O H} \\
\left.\mathbf{( m}^{-1}\right)\end{array}$ & $\begin{array}{c}\text { Vibrasi } \\
\mathbf{C H}_{\mathbf{3}}\end{array}$ & $\begin{array}{c}\text { Vibrasi } \\
\text { regang } \\
\mathbf{C = 0}\end{array}$ & $\begin{array}{c}\text { Vibrasi } \\
\text { regang } \\
\mathbf{C = C}\end{array}$ & $\begin{array}{c}\text { Vibrasi } \\
\text { regang } \\
\mathbf{C}-\mathbf{O}\end{array}$ \\
\hline Oksida & $\begin{array}{c}3430 \text { dan } \\
\text { Grafena }\end{array}$ & $\begin{array}{c}2930 \text { dan } \\
2850\end{array}$ & 1720 & 1630 & 1050 \\
\hline $\begin{array}{c}\text { Oksida } \\
\text { Grafena }\end{array}$ & $\begin{array}{c}3430 \text { dan } \\
1373\end{array}$ & $\begin{array}{c}2930 \text { dan } \\
2850\end{array}$ & 1720 & 1630 & 1050 \\
Tereduksi & & & & & \\
\hline
\end{tabular}

Seperti yang telah dirangkum pada Tabel 1, spektrum oksida grafena menunjukkan puncak yang lebar pada bilangan gelombang sekitar 3430 and $1373 \mathrm{~cm}^{-1}$, yang berhubungan dengan vibrasi regangan dari gugus $\mathrm{OH}$. Puncak pada bilangan gelombang $2930 \mathrm{~cm}^{-1}$ dan $2850 \mathrm{~cm}^{-1}$ menunjukkan vibrasi regangan simetris dan anti simetris dari $\mathrm{CH}_{3}$.

Puncak pada 1720 dan $1630 \mathrm{~cm}^{-1}$ berkenaan dengan pola vibrasi regangan dari $\mathrm{C}=\mathrm{O}$ dan ikatan $\mathrm{C}=\mathrm{C}$ aromatik. Puncak pada $1050 \mathrm{~cm}^{-1}$ menunjukkan vibrasi regangan dari C-O. kehadiran gugus fungsi yang mengandung oksigen menandakan bahwa grafit telah teroksidasi.

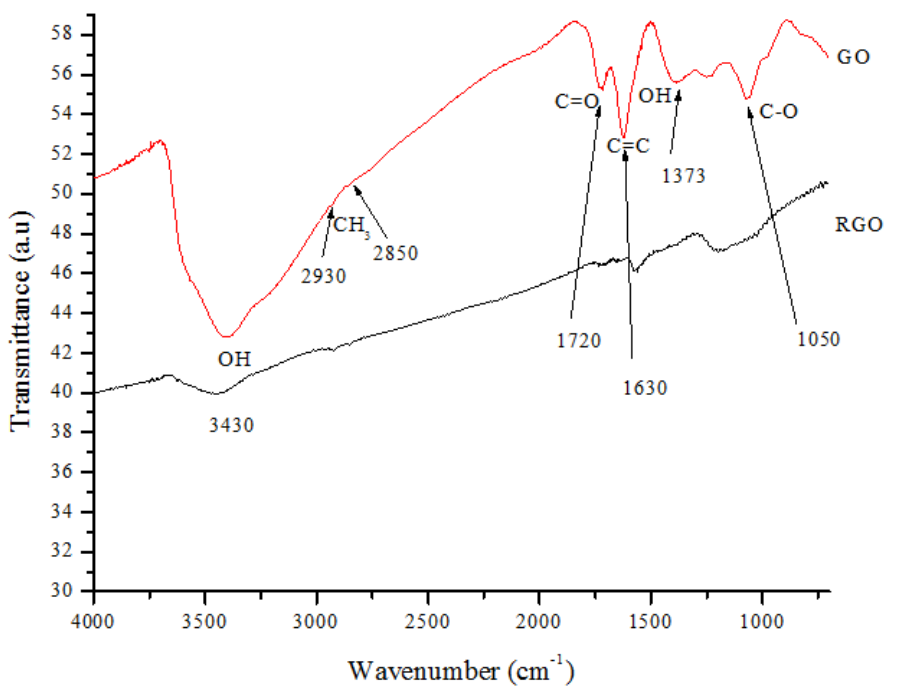

Gambar 2 Spektra FT-IR oksida grafena (GO) dan oksida grafena tereduksi (RGO)

Spektrum okside grpahene tereduksi sama dengan oksida grafena, namum dengan intensitas puncak lebih rendah. Intensitas puncak pada $3430 \mathrm{~cm}^{-1}$ berkenaan dengan OH. Sementara itu, pita pada $1700-1000 \mathrm{~cm}^{-1}$ menunjukkan tumpang tindih gugus yang mengandung oksigen. Intensitas yang lebih rendah dibandingkan dengan oksida grafena, menunjukkan bahwa sebagian besar gugus fungsi oksigen telah hilang dari oksida grafena. Hal ini menunjukkan berhasilnya proses reduksi oksida grafena dengan menggunakan asam format. 


\section{Karakterisasi XRD}

Gambar 2 menunjukkan pola XRD dari grafit (G), oksida grafena (GO) dan oksida grafena tereduksi (RGO). Data XRD menunjukkan bahwa grafit memiliki puncak yang tajam pada $2 \theta=26.48$, yang berkenaan dengan struktur lapis yang sangat tersususun sepanjang bidang (002) dengan $d$-spacing 3.36 ̊ (Mitra et al., 2013).

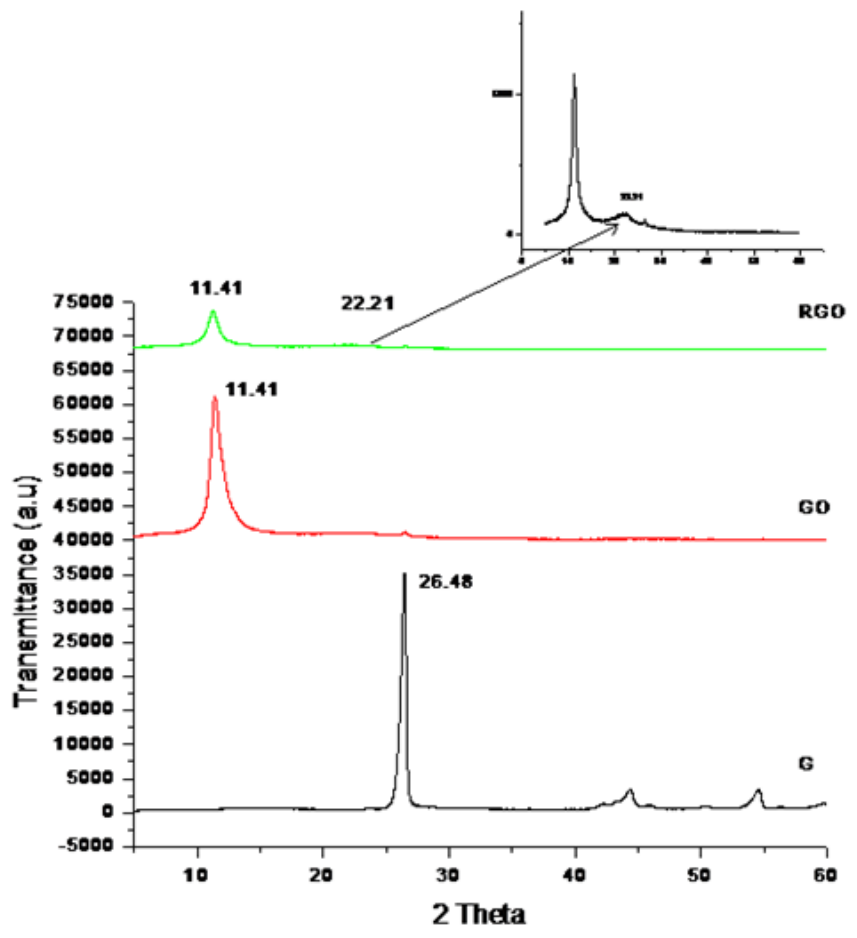

Gambar 3. Pola XRD dari grafit (G), oksida grafena (GO), okisda grafena tereduksi (RGO) dan inset dari okisda grafena tereduksi (RGO).

Setelah proses oksidasi, bidang (002) berpindah ke sudut yang lebih rendah yakni pada $2 \theta=11.41$. Ini menandakan peningkatan $d$-spacing menjadi 7.75 spacing berkenaan dengan kehadiran gugus fungsional oksigen dan hidroksil pada struktur lapisan karbon. Disamping puncak pada $2 \theta=11.41^{\circ}$, oksida grafena tereduksi juga menunjukkan puncak baru yang lebar pada $2 \theta=22.21^{\circ}$, yang berhubungan dengan $d$-spacing yakni $4.00 \AA \AA$. Kehadiran puncak yang lebar pada $2 \theta=22.21$ adalah karena penghilangan atom-atom oksigen selama proses reduksi (Thema, Moloto, \& Dikio, 2013).

\section{Penghalusan Dengan Metode Le Bail}

Untuk menentukan parameter kisi dari grafit, oksida grafena dan oksida grafena tereduksi, penghalusan data XRD dikerjakan dengan menggunakan software Rietica dengan metode Le Bail. 


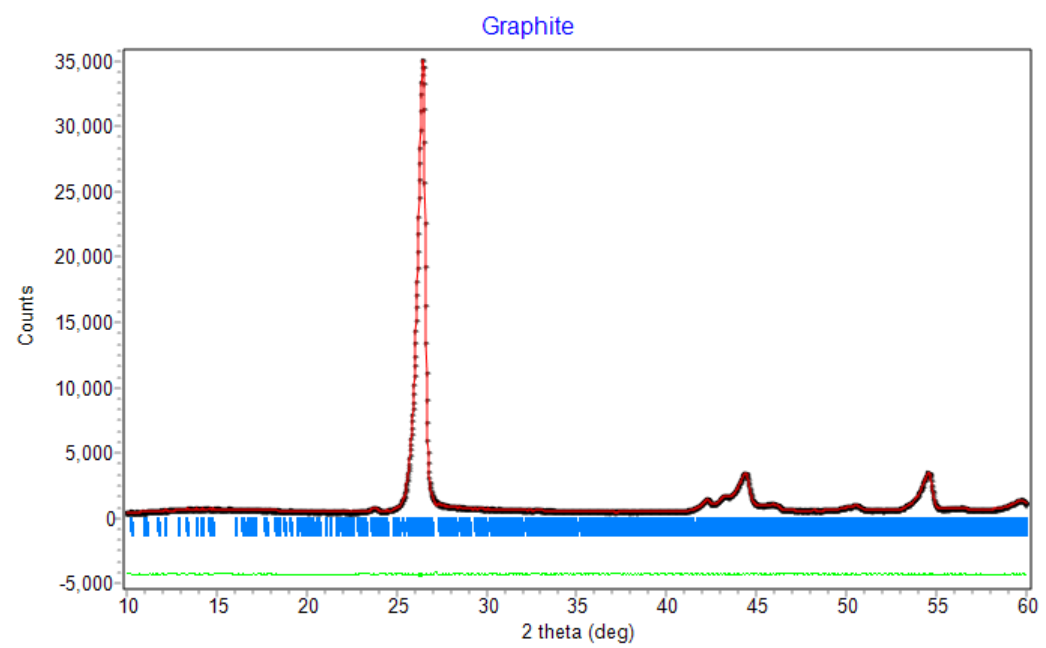

Gambar 4. Penghalusan data XRD dari Grafit. Tanda (+) merupakan data pengamatan XRD, garis merah merupakan hasil perhitungan, garis biru menunjukkan posisi Brag dan garis hijau merupakan perbedaan antara data pengamatan dan perhitungan.

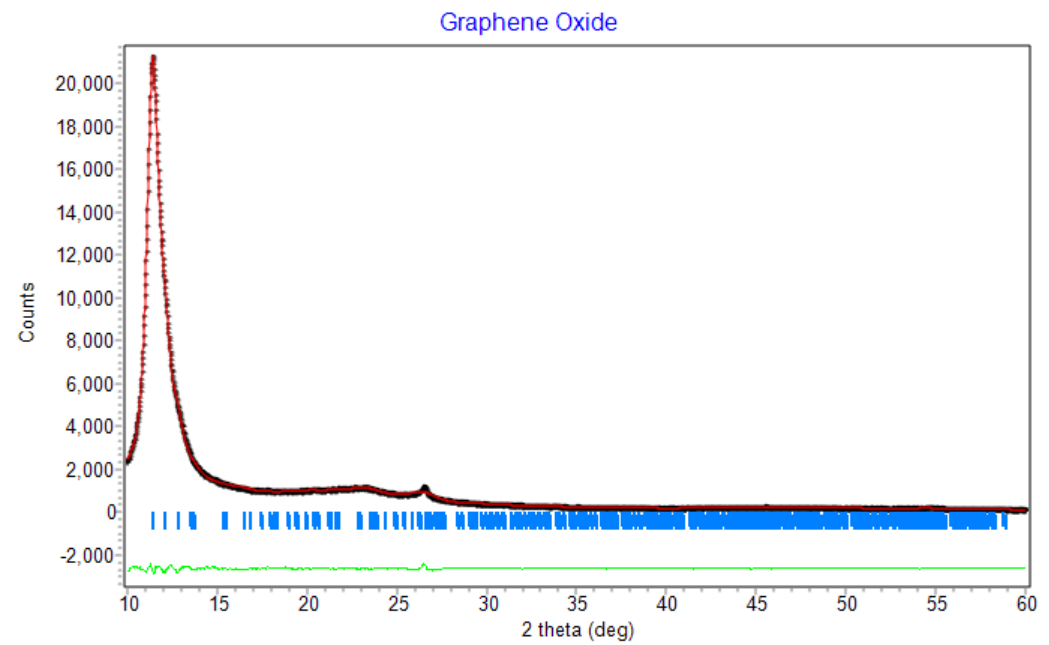

Gambar 5. Penghalusan data XRD dari Oksida Grafena. Tanda (+) merupakan data pengamatan XRD, garis merah merupakan hasil perhitungan, garis biru menunjukkan posisi Brag dan garis hijau merupakan perbedaan antara data pengamatan dan perhitungan. 


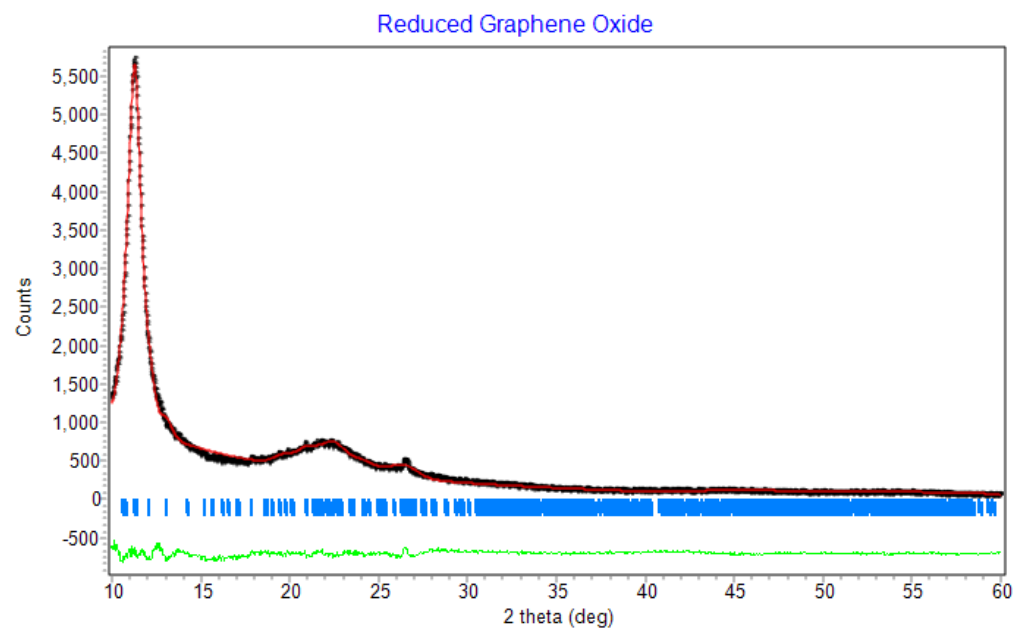

Gambar 6. Penghalusan data XRD dari Oksida Grafena Tereduksi. Tanda (+) merupakan data pengamatan XRD, garis merah merupakan hasil perhitungan, garis biru menunjukkan posisi Brag dan garis hijau merupakan perbedaan antara data pengamatan dan perhitungan.

Tabel 2. Parameter kisi dari grafit, oksida grafena dan oksida grafena tereduksi yang diperoleh dari penghalusan XRD.

\begin{tabular}{cccc}
\hline \multirow{2}{*}{\begin{tabular}{c} 
Karameter \\
\cline { 2 - 4 }
\end{tabular}} & Grafit & Oksida Grafena & $\begin{array}{c}\text { Oksida Grafena } \\
\text { Tereduksi }\end{array}$ \\
\cline { 2 - 4 } Grup Ruang & P B C A & P B C A & P B C A \\
\hline$a(\AA)$ & 18.18770 & 9.12390 & 46.61160 \\
\hline$b(\AA)$ & 17.18840 & 20.32220 & 5.82000 \\
\hline$c(\AA)$ & 20.73410 & 21.05350 & $90^{\circ}$ \\
\hline$\alpha=\beta=\gamma$ & $90^{\circ}$ & $90^{\circ}$ & 4523.291504 \\
\hline $\mathrm{V}\left(\AA^{3}\right)$ & 6481.873047 & 3903.689941 & 3.461 \\
\hline$\chi^{2}$ & 2.184 & 7.528 & \\
\hline
\end{tabular}

Pada penelitian ini, parameter sel dari grafit yang dilaporkan oleh Chia et al (Chia et al., 2012) digunakan sebagai referensi untuk proses penghalusan dimana $a=$ 18.2275.82 ̊, $b=17.9651 .03 \AA, c=20.7428 \AA$ dan $\alpha=\beta=\gamma=90^{\circ}$. Gambar 3 hingga 5 menunjukkan proses penyesuaian data XRD untuk grafit, oksida grafena dan oksida grafena tereduksi. Telah ditemukan kesesuian antara pola difraksi yang diukur dengan pola penyesuaian untuk semua sampel. Parameter kisi dari semua sampel disajikan pada 
Tabel 2. Perubahan pada parameter kisi ditemukan setelah proses oksidasi dan reduksi, terutama pada $a$ dan $b$. Parameter $a$ dan $b$ dari oksida grafena aagak sedikit lebih tinggi dibandingkan dengan grafit oleh karena proses oksidasi. Kemudian, ketika oksida grafena direduksi menjadi oksida grafena tereduksi, parameter $a$ dan $b$ cenderung menurun. Adapun grup ruang dari ketiga sampel tidak berubah yakni P B C A. Sementara itu, hasil kalkulasi penentuan parameter kisi menunjukkan hasil yang baik, yang ditandai dengan nilai chi square $\left(\chi^{2}\right)$ yang relatif rendah.

\section{SIMPULAN}

Oksida grafena tereduksi telah berhasil disintesis dengan menggunakan metode modifikasi Hummer untuk memperoleh oksida grafena dan menggunakan asam format untuk memperoleh oksida grafena tereduksi. Produk yang diperoleh dikarakterisasi dengan menggunakan FT-IR dan XRD. Karakterisasi dengan FT-IR dan XRD menunjukkan bahwa oksida grafena tereduksi telah berhasil dihasilkan menggunakan asam format sebagai agen pereduksi.

\section{UCAPAN TERIMA KASIH}

Penelitian ini didukung pendanaannya oleh beasiswa Kaltim Cemerlang serta bantuan dari staff laboratorium King Mongkut's University of Technology Thonburi's (Thailand).

\section{DAFTAR RUJUKAN}

Chia, Siew-Peng, Ganguly, Li, R., So, Y., \& Cheuk-Wai. (2012). Reactivity of a Distannylene toward Potassium Graphite: Synthesis of a Stannylidenide Anion. $31,6415$.

Daniel, R., Dreyer, Park, S., Christopher, W., Bielawski, \& Ruoff, R. S. (2009). The chemistry of graphene oxide. Chemical Society Reviews, 39, 228-240.

Dubin, S., Gilje, S., Wang, K., Tung, V. C., Cha, K., Hall, A. S., Kaner, R. B. (2010). A one-step, solvothermal reduction method forproducing reduced graphene oxide dispersions in organic solvents. American Chemical Society Nano, 4, 3845-3852.

Hummers, W. S., \& Offeman, R. E. (1958). Preparation Graphitic Oxide. American Chemical Society, 80, 1339-1339.

Kudin, K. N., Ozbas, B., Schniepp, H. C., Prudhomme, R. K., Aksay, I. A., \& Car, R. (2007). Raman Spectra of Graphite Oxide and Functionalized Graphene Sheets. Nano Letter, 8, 36-41.

Lerf, A. H., He, M., \& Kilnowski, F. J. (1998). Structure of Graphene Oxide Revisited. Physics Chemistry, 102, 4477-4482.

Mitra, M., Chatterjee, K., Kargupta, K., Ganguly, S., \& Banerjee, D. (2013). Reduction of graphene oxide through a green and metal-free approach using formic acid. Diamond and Related Materials, 37, 74-79. doi:10.1016/j.diamond.2013.05.003

Park, O. K., Hahm, M. G., Lee, S., Joh, H. I., Na, S. I., Vajtai, R., . . Ajayan, P. M. (2012). In situ synthesis of thermochemically reduced graphene oxide conducting nanocomposites. Nano Letter, 12(4), 1789-1793. doi:10.1021/nl203803d

Park, S., An, J., Potts, J. R., Velamakanni, A., Murali, S., \& Ruoff, R. S. (2011). Hydrazine-reduction of graphite- and graphene oxide. Carbon, 49(9), 3019-3023. doi:10.1016/j.carbon.2011.02.071 
Dalton : Jurnal Pendidikan Kimia dan Ilmu Kimia, Volume 3 Nomor 1, Mei 2020

Schniepp, H. C., Li, J. L., McAllister, M. J., Sai, H., Herrera, Alonso, M., .Aksay, I. A. (2006). Functionalized Single Graphene Sheets Derived from Splitting Graphite Oxide. The Journal of PhysicalChemistry, 17, 8535-8539.

Stankovich, S., Dikin, D. A., Piner, R. D., Kohlhaas, K. A., Kleinhammes, A., \& Jia, Y. (2007). Synthesis of graphene-based nanosheets via chemical reduction of exfoliated graphite oxide. Carbon, 45, 1558.

Su, P. G., \& Chiou, C. F. (2014). Electrical and Humidity-Sensing Properties of Reduced Graphene Oxide Thin Film Fabricated by Layer-by Layer with Covalent Anchoring on Flexible Substrate. Sensors and Actuator, 9, 18.

Thema, F. T., Moloto, M. J., \& Dikio, E. D. (2013). Synthesis and Characterization of Graphene Thin Films by Chemical Reduction of Exfoliated and Intercalated Graphite Oxide. Journal of Chemistry, 2013 3-5.

Wu, Z. S., Ren, W., Gao, L., Liu, B., Jia, C., \& Cheng, H. M. (2009). Synthesis of high quality graphene with a pre-determined number of layers. Carbon, 47, 493-499. 